\title{
25 Research Soure \\ Root resorption in patients treated with self-ligating or conventional brackets: A systematic review
}

Jiye Xie

Kunming Medical University Affiliated Stomatology Hospital

\section{Kang Yin}

Kunming Medical University Affiliated Stomatology Hospital

\section{Xin Wen}

Kunming Medical University Affiliated Stomatology Hospital

Wei He

Kunming Medical University Affiliated Stomatology Hospital

Yanhua Xu ( $\nabla$ xuyanhua18@163.com )

Kunming Medical University Affiliated Stomatology Hospital https://orcid.org/0000-0002-6805-1299

\section{Research article}

Keywords: Systematic review, Self-ligating bracket, Conventional bracket, Root resorption

Posted Date: January 22nd, 2020

DOI: https://doi.org/10.21203/rs.2.21505/v1

License: (c) (1) This work is licensed under a Creative Commons Attribution 4.0 International License. Read Full License 


\section{Abstract}

Background: To compare the degree of external apical root resorption (EARR) in patients using selfligating brackets with conventional brackets in a long run.

Methods: Electronic search was made in databases including PubMed, OVID, the Cochrane Library, EMBASE, FMRS, CBM, CNKI, VIP and WanFang Data until November 2019 to retrievalled randomized controlled trials and clinical controlled trials that compared the EARR between patients using self-ligating or conventional brackets. What's more, manual search was made in NLM, SIGLE, Campbell library, WHOLIS, Chinese Journal of Evidence-based Medicine and the Journal of Orthodontics. Literature filtering, data extraction and methodological quality evaluation were finished independently by two researchers and disagreements were solved by a third reviewer. Original outcome data, if possible, were subjected to statistical pooling by Review Manager 5.3 for Meta analysis.

Results: Through a predefined search strategy, ten studies were included in the systematic review and nine eligible studies were pooled in meta-analysis. There was a significant difference between selfligating and conventional brackets in terms of the value of EARR in maxillary central incisors $(P=0.01$; SMD: $-0.42 \mathrm{~mm} ; 95 \% \mathrm{Cl}:-0.76,-0.09)$ in a long run. No significant difference in maxillary lateral incisors ( $P=0.07$; SMD: -0.17 ; 95\%Cl: $-0.35,0.01)$, mandibular central incisors $(P=0.69 ; \mathrm{SMD}: 0.04 ; 95 \% \mathrm{Cl}:-0.17$, $0.26)$ and mandibular lateral incisors ( $P=0.38$; SMD: $-0.10 ; 95 \% \mathrm{Cl}:-0.32,0.12)$.

Conclusions: Self-ligating brackets have a long-term effect in protecting maxillary central incisors from the EARR compared to conventional brackets. However, self-ligating brackets were not superior to conventional brackets in reducing the EARR of maxillary lateral incisors, mandible central incisors and mandible lateral incisors.

\section{Background}

External apical root resorption (EARR) which could be defined as the blunting and shortening of root apex caused by the pathologic loss of the cementum and dentine is considered as one of the most serious adverse effect during orthodontic treatment. ${ }^{1}$

Although EARR has been considered as an iatrogenic problem associated with orthodontic treatment, the relationship between orthodontic treatment and EARR has never been fully answered. EARR presents with a multifactorial etiology, and it is the comprehensive result of individual biological variation, genetic susceptibility and mechanical factors. ${ }^{2}$ Studies have shown that force magnitudes and the distance of tooth movement maybe contribute to the incidence of EARR during orthodontic treatment. ${ }^{3,4}$ In addition, it appears that there might be a positive correlation between treatment time, type of orthodontic force and treatment techniques, ${ }^{5}$ and EARR.

With the continuous updating of orthodontic appliances, self-ligating brackets have been widely used for the advantages of less friction, faster tooth movement, less orthodontic pain, more comfortable wearing 
and shorter chair time. ${ }^{6}$ Methods of arch wire ligation are different between self-ligating brackets and conventional brackets. And then, there is the question that whether self-ligating brackets would have different effect on EARR compared with conventional brackets. Despite these was a systematic review compared the EARR between patients using self-ligating or conventional brackets, ${ }^{7}$ it included both shortterm (about 6 months) studies and long-term (after finishing treatment) studies. It is limited evidence because the treatment duration has been considered as a risk factor to the development of EARR. ${ }^{5}$ This systematic review firstly only included long-term studies so that it can comprehensively and objectively evaluates the EARR in fixed orthodontic treatment with self-ligating and conventional brackets in a long run.

\section{Methods}

\section{Protocol}

The study protocol followed the PRISMA (Preferred Reporting Items for Systematic Review and MetaAnalyses) guidelines of the Preferred Reporting Items for Systematic Reviews and Meta-Analyses (PRISMA) statement ${ }^{8}$ and the recommendations of the Cochrane collaboration. ${ }^{9}$ The PICO question (population [P], intervention [I], comparison [C], and outcome [O]) was developed as follow: In patients treated with fixed orthodontic $(\mathrm{P})$, does the self-ligating brackets $(\mathrm{I})$ compared to conventional brackets (C) make less degree of external apical root resorption (0) based on randomized control trials (RCTs) and clinical controlled trials (CCTs)?

\section{Search Strategy}

An electronic literature search was conducted through databases including PubMed, OVID, the Cochrane Library, EMBASE, FMRS, CBM, CNKI, VIP and WanFang Data. Furthermore, related articles were handsearched in NLM (National Library of Medicine), SIGLE (System for Information on Grey Literature in Europe), Campbell library, WHOLIS (World Health Organization's library database), Chinese Journal of Evidence-based Medicine and the Journal of Orthodontics. Terms used in the search included root resorption, root shortening, root alternation, self-ligating and self-ligating bracket. Retrieval time was set from database establishment to November 2019. No language restriction was applied during the literature search.

Criteria for included studies

The inclusion criteria were as follows: (1) Types of studies: randomized controlled trials (RCTs) or controlled clinical trials (CCTs), prospective and retrospective controlled studies; (2) Types of participants: healthy patients who required fixed orthodontic treatment; (3) Types of intervention: the experimental group and the control group used self-ligating brackets and conventional brackets; (4) Outcomes: maxillary and/or mandibular incisors root lengths before and after treatment were measured, and then calculated the reduction of root length (in millimeters and in percentage). 
The exclusion criteria were as follows: (1) Studies involving patients with systemic diseases or primary periodontal disease before orthodontic treatment; (2) The reduction of root length been measured was not comparing before treatment with after treatment but in other treatment time; (3) Not the long-term (after finishing treatment) studies; (4) Animal experiments; (5) Reviews, case reports or abstracts.

Data Extraction and quality analysis

Studies were extracted and recorded independently by two reviewers (J.X and X.W) and in duplicate using a customized data collection form, on the following items: author and year of publication, study design, comparisons, participants (numbers, gender, age) and outcomes (EARR, measurement approach, evaluated teeth).

The quality assessment of RCT articles was performed referring to Cochrane Handbook for Systematic Reviews of Interventions(version 5.1.0). ${ }^{10}$ Meanwhile, quality scores were calculated by a modified version of the method described by Jadad. ${ }^{9}$ Otherwise, the quality evaluation of CCT articles were reformed according to the standards described in the Cochrane Handbook for Systematic Reviews Interventions and Liu. ${ }^{12}$ The methods and results sections of each article were read and scored by two readers (J.X and X.W) independently. Then evaluators discussed their extracted data, and when discrepancy occurred, it was solved by discussing with a third reviewer (K.Y).

Data Analysis

In this systematic review, evaluation of EARR mainly includes maxillary central incisors, maxillary lateral incisors, mandibular central incisors and mandibular lateral incisors. The Review Manager 5.3 software was used for the meta-analysis of quantitative data. Statistical heterogeneity within or between groups was assessed by the Cochrane's test. The outcome measure was standardized mean difference (SMD).The heterogeneity of recruited studies was explored by $\mathrm{I}^{2}$ statistic. If there was no substantial heterogeneity $\left(\mathrm{I}^{2}<50 \%\right)$, outcomes would be pooled for the meta-analysis with the fixed effect model. Otherwise, the random effect model would be adopted. Descriptive assessment was done when the statistical synthesis of data failed.

\section{Results}

Description of Studies

Finally, ten studies ${ }^{13-22}$ were included in this systematic review, among which, one was categorized as $\mathrm{RCT}^{13}$ and the others were CCTs ${ }^{14-22}$. Nine studies ${ }^{13-17,19-22}$ were pooled in meta-analysis. The flow of the selection process is demonstrated in Fig. 1. Summary details of included studies are given in Table 1.

Methodological Quality of Included Studies 
Of the ten included studies, the one $\mathrm{RCT}^{13}$ was high quality, and the nine CCTs ${ }^{14-22}$ were $\mathrm{A}$ grade. The methodological quality for RCT and CCT trials are presented in Table 2 and Table 3, respectively.

External apical root resorption

Ten studies ${ }^{13-22}$ were included in this systematic review, but one study ${ }^{18}$ did not included in the metaanalysis due to the lack of comparability of data. The feasible data was statistically pooled in metaanalysis to compare the values of EARR between self-ligating and conventional brackets in a long run. A Forest plot is demonstrated in Fig. 2. According to the teeth position, the values of EARR during fixed orthodontic treatment were grouped as maxillary central incisors, maxillary lateral incisors, mandibular central incisors and mandibular lateral incisors.

Nine articles ${ }^{13-17,19-22}$ reported EARR of maxillary central incisors, and the meta-analysis results showed the SMD $(95 \% \mathrm{Cl})$ was $-0.42(-0.76,-0.09)$, with a significant difference between self-ligating and conventional brackets ( $P=0.01$ ) (Fig. 2). Eight studies ${ }^{13-15,17-22}$ investigated EARR of maxillary lateral incisors and five studies ${ }^{15,17,19-21}$ were categorized into both EARR of mandibular central incisors and EARR of mandibular lateral incisors. Besides, the meta-analysis indicates that there was no significant difference in maxillary lateral incisors ( $P=0.07$; SMD: $-0.17 ; 95 \% \mathrm{Cl}:-0.35,0.01)$ (Fig. 2), mandibular central incisors ( $P=0.69$; SMD: $0.04 ; 95 \% \mathrm{Cl}$ : $-0.17,0.26)$ (Fig. 2) and mandibular lateral incisors $(P=0.38$; SMD: $-0.10 ; 95 \% \mathrm{Cl}:-0.32,0.12)$ (Fig. 2).

Table 1. Summary details of included studies. 


\begin{tabular}{|c|c|c|c|c|c|}
\hline $\begin{array}{l}\text { Study ID } \\
\text { Author } \\
\text { (Year) }\end{array}$ & $\begin{array}{l}\text { Design } \\
\text { Study }\end{array}$ & Comparisons & Participants & Outcomes (Method) & $\begin{array}{l}\text { Evaluated } \\
\text { Teeth }\end{array}$ \\
\hline $\begin{array}{l}\text { Liu Y et al. } \\
2016^{13}\end{array}$ & RCT & $\begin{array}{l}\text { SLB(DamonQ, Ormco) vs } \\
\text { CB(3M) }\end{array}$ & $\begin{array}{l}\text { SLB:n=25(M11,F14;15.29 } \pm 1.57 y) \\
C B: n=25(M 9, F 16 ; 15.16 \pm 1.72 y)\end{array}$ & $\begin{array}{l}\text { Root resorption in } \\
\text { millimeter } \\
(\mathrm{CBCT})\end{array}$ & $\begin{array}{l}(11,21), \\
(12,22)\end{array}$ \\
\hline $\begin{array}{l}\text { Yang et al. } \\
2012^{14}\end{array}$ & ССТ & SLB(Smartclip, 3M) vs & $\begin{array}{l}\text { SLB:n=16(13.2y) } \\
\text { CB:n=16(13.2y) }\end{array}$ & $\begin{array}{l}\text { Root resorption in } \\
\text { millimeter } \\
\text { (panoramic } \\
\text { radiographs) }\end{array}$ & $\begin{array}{l}(11,21), \\
(12,22)\end{array}$ \\
\hline $\begin{array}{l}\text { Liu XQ et } \\
\text { al. }\end{array}$ & ССТ & $\begin{array}{l}\text { SLB(Damon3MX,Ormco) vs } \\
\text { CB }\end{array}$ & $\begin{array}{l}\text { SLB:n=15(M7,F8;15.13y) } \\
\text { CB:n=15(M9,F6;14.93y) }\end{array}$ & $\begin{array}{l}\text { Root resorption in } \\
\text { millimeter }\end{array}$ & $\begin{array}{l}(11,21), \\
(12,22),\end{array}$ \\
\hline $2012^{15}$ & & & & $\begin{array}{l}\text { (panoramic } \\
\text { radiographs) }\end{array}$ & $\begin{array}{l}(31,42), \\
(32,42)\end{array}$ \\
\hline $\begin{array}{l}\text { Lu et al. } \\
2017^{16}\end{array}$ & ССT & SLB(DamonQ, Ormco) vs & $\begin{array}{l}\text { SLB: } n=15(13.3 \pm 1.4 y) \\
\text { CB:n=15(13.4 } \pm 1.3 y)\end{array}$ & $\begin{array}{l}\text { Root resorption in } \\
\text { millimeter }\end{array}$ & $(11,21)$ \\
\hline & & & & $(\mathrm{CBCT})$ & \\
\hline $\begin{array}{l}\text { Blake et al. } \\
1995^{17}\end{array}$ & CCT & $\begin{array}{l}\text { SLB(Speed, Strite) vs } \\
\text { CB }\end{array}$ & $\begin{array}{l}\text { SLB:n=30(M12,F18;12.8 } \pm 2.3 y) \\
\text { CB:n=33(M16,F17;13 } \pm 2.5 y)\end{array}$ & $\begin{array}{l}\text { Root resorption in } \\
\text { percentage }\end{array}$ & $\begin{array}{l}(11,21), \\
(12,22),\end{array}$ \\
\hline & & & & (periapical radiograph) & $\begin{array}{l}(31,41), \\
(32,42)\end{array}$ \\
\hline $\begin{array}{l}\text { Pandis et } \\
\text { al. }\end{array}$ & CCT & $\begin{array}{l}\text { SLB(Damon2, Ormco) vs } \\
\text { CB(Microarch, GAC) }\end{array}$ & $\begin{array}{l}\text { SLB:n=48(M17,F31;13.29 } \pm 1.57 y) \\
\text { CB:n=48(M12,F36;13.14 } 1.73 y)\end{array}$ & $\begin{array}{l}\text { Root resorption in } \\
\text { millimeter }\end{array}$ & $\begin{array}{l}(11,21), \\
(12,22)\end{array}$ \\
\hline $2008^{18}$ & & & & $\begin{array}{l}\text { (panoramic } \\
\text { radiographs) }\end{array}$ & \\
\hline $\begin{array}{l}\text { Chen et al. } \\
2015^{19}\end{array}$ & ССТ & $\begin{array}{l}\text { SLB(Damon3, Ormco) vs } \\
\mathrm{CB}(3 \mathrm{M})\end{array}$ & $\begin{array}{l}\text { SLB:n=35(M17,F18;13.52 } \pm 2.84 y) \\
\text { CB:n=35(M16,F19;13.42 } \pm 2.50 y)\end{array}$ & $\begin{array}{l}\text { Root resorption in } \\
\text { millimeter }\end{array}$ & $\begin{array}{l}(11,21), \\
(12,22),\end{array}$ \\
\hline & & & & $\begin{array}{l}\text { (periapical } \\
\text { radiographs) }\end{array}$ & $\begin{array}{l}(31,41), \\
(32,42)\end{array}$ \\
\hline $\begin{array}{l}\text { Sepolia et } \\
\text { al. }\end{array}$ & ССТ & $\begin{array}{l}\text { SLB vs } \\
\text { CB }\end{array}$ & $\begin{array}{l}\text { SLB:n=70(13.92 } \pm 3.01 y) \\
\text { CB:n=70(13.81 } \pm 2.940 y)\end{array}$ & $\begin{array}{l}\text { Root resorption in } \\
\text { millimeter }\end{array}$ & $\begin{array}{l}(11,21), \\
(12,22),\end{array}$ \\
\hline $2016^{20}$ & & & & $\begin{array}{l}\text { (periapical } \\
\text { radiographs) }\end{array}$ & $\begin{array}{l}(31,41), \\
(32,42)\end{array}$ \\
\hline Eissa et al. & ССТ & SLB(DamonQ, Ormco) vs & SLB:n=11(M4,F7;17.71 $\pm 2.22 y)$ & $\begin{array}{l}\text { Root resorption in } \\
\text { millimeter }\end{array}$ & $\begin{array}{l}(11,21), \\
(12,22),\end{array}$ \\
\hline $2018^{21}$ & & $\mathrm{CB}$ & $\mathrm{CB}: \mathrm{n}=11(\mathrm{M} 6, \mathrm{~F} 5 ; 17.34 \pm 2.38 \mathrm{y})$ & (CBCT) & $\begin{array}{l}(31,41), \\
(32,42)\end{array}$ \\
\hline Qin et al. & ССТ & SLB(Damon3, Ormco) vs & SLB:n=49(M25,F24;15.15 $\pm 4.52 y)$ & $\begin{array}{l}\text { Root resorption in } \\
\text { millimeter }\end{array}$ & $\begin{array}{l}(11,21), \\
(12,22)\end{array}$ \\
\hline $2019^{22}$ & & $\mathrm{CB}(3 \mathrm{M})$ & $C B: n=49(M 26, F 23 ; 15.21 \pm 4.43 y)$ & $\begin{array}{l}\text { (panoramic } \\
\text { radiographs) }\end{array}$ & \\
\hline
\end{tabular}


Table 2. Methodological quality of selected RCT trial ${ }^{\mathrm{a}}$

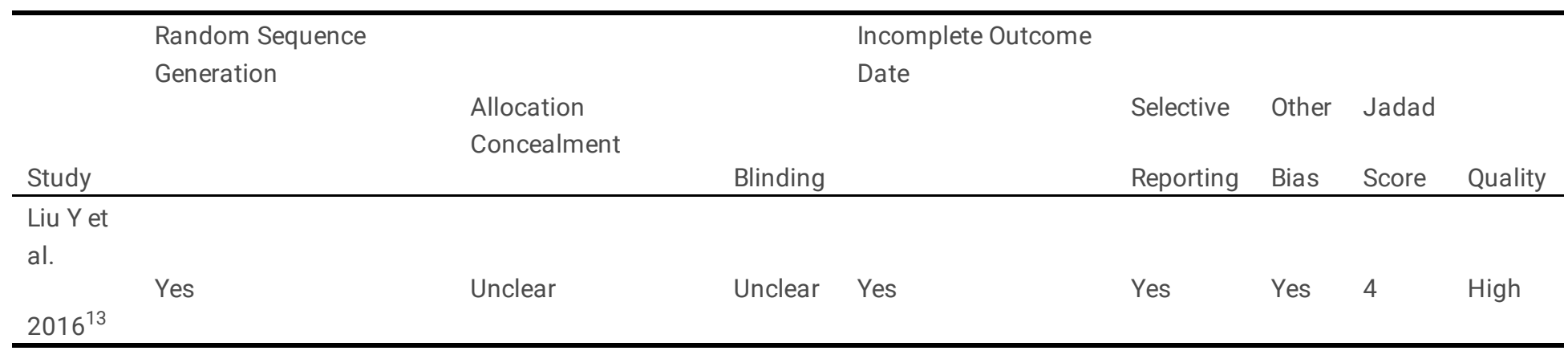

Quality was categorized as low quality (1-3 Jadad scores) and high quality (4-7 Jadad scores).

ible 3. Methodological quality of selected CCT trials ${ }^{a}$ 


\begin{tabular}{|c|c|c|c|c|c|c|c|c|}
\hline Study & $\begin{array}{c}\text { Diagnostic } \\
\text { Criteria }\end{array}$ & $\begin{array}{l}\text { Grouping } \\
\text { Method }\end{array}$ & Blinding & $\begin{array}{c}\text { Baseline } \\
\text { Consistency }\end{array}$ & $\begin{array}{c}\text { Confounder } \\
\text { Control }\end{array}$ & $\begin{array}{l}\text { Lost to } \\
\text { Treatment }\end{array}$ & Score & Grade \\
\hline $\begin{array}{c}\text { Yang et } \\
\text { al. }\end{array}$ & $\begin{array}{c}\text { Clinical } \\
\text { Diagnosis }\end{array}$ & $\begin{array}{c}\text { Not } \\
\text { Mentioned }\end{array}$ & Not Mentioned & & & & & \\
\hline $2012^{14}$ & & & & Better & Better & No Lost & 8 & A \\
\hline Liu X et al. & $\begin{array}{c}\text { Clinical } \\
\text { Diagnosis }\end{array}$ & $\begin{array}{c}\text { Not } \\
\text { Mentioned }\end{array}$ & Not Mentioned & & & & & \\
\hline $\begin{array}{l}2012^{15} \\
\text { Lu et al. }\end{array}$ & Clinical & Not & Not Mentioned & Better & Better & No Lost & 8 & A \\
\hline $2017^{16}$ & Diagnosis & Mentioned & & Better & Good & No Lost & 7 & A \\
\hline $\begin{array}{c}\text { Blake et } \\
\text { al. }\end{array}$ & $\begin{array}{c}\text { Clinical } \\
\text { Diagnosis }\end{array}$ & $\begin{array}{c}\text { Not } \\
\text { Mentioned }\end{array}$ & Not Mentioned & & & & & \\
\hline $1995^{17}$ & & & & Better & Better & No Lost & 8 & A \\
\hline $\begin{array}{l}\text { Pandis et } \\
\text { al. }\end{array}$ & $\begin{array}{c}\text { Clinical } \\
\text { Diagnosis }\end{array}$ & $\begin{array}{c}\text { Not } \\
\text { Mentioned }\end{array}$ & Not Mentioned & & & & & \\
\hline $2008^{18}$ & & & & Better & Better & No Lost & 8 & A \\
\hline $\begin{array}{c}\text { Chen et } \\
\text { al. }\end{array}$ & $\begin{array}{c}\text { Clinical } \\
\text { Diagnosis }\end{array}$ & $\begin{array}{c}\text { Not } \\
\text { Mentioned }\end{array}$ & Not Mentioned & & & & & \\
\hline $2015^{19}$ & & & & Better & Better & No Lost & 8 & A \\
\hline $\begin{array}{l}\text { Sepolia et } \\
\text { al. }\end{array}$ & $\begin{array}{c}\text { Clinical } \\
\text { Diagnosis }\end{array}$ & $\begin{array}{c}\text { Not } \\
\text { Mentioned }\end{array}$ & Not Mentioned & & & & & \\
\hline $2016^{20}$ & & & & Better & Better & No Lost & 8 & A \\
\hline $\begin{array}{c}\text { Eissa et } \\
\text { al. }\end{array}$ & $\begin{array}{c}\text { Clinical } \\
\text { Diagnosis }\end{array}$ & $\begin{array}{c}\text { Not } \\
\text { Mentioned }\end{array}$ & $\begin{array}{l}\text { Mentioned and } \\
\text { described }\end{array}$ & & & & & \\
\hline $2018^{21}$ & & & & Better & Better & No Lost & 10 & A \\
\hline $\begin{array}{l}\text { Qin et al. } \\
2019^{22}\end{array}$ & $\begin{array}{c}\text { Clinical } \\
\text { Diagnosis }\end{array}$ & $\begin{array}{c}\text { Not } \\
\text { Mentioned }\end{array}$ & Not Mentioned & Better & Better & No Lost & 8 & A \\
\hline
\end{tabular}

ity was categorized as A grade(10-12 score), B grade(6-9 score), and C grade(0-5score).

\section{Discussion}

\section{External apical root resorption}

A recent boost has been observed in the use of self-ligating brackets may be due to its certain advantages. One of the significant advantages is less friction, which makes teeth slide along the arch wire under the continuous orthodontic light force and reduces the force on the root. ${ }^{22}$ However, conventional brackets induce teeth under the larger intermittent orthodontic force because of the fatigue of stainless steel ligature or the aging of elastometric rings. Studies have shown that the degree of EARR caused by continuous force is more than that caused by intermittent force. ${ }^{24,25}$ Besides, the continuous heavy force will bring more EARR than the continuous light force ${ }^{24,25}$ Aside form force type and 
magnitude, EARR is also influenced by many factors including malocclusion, amount of tooth movement, treatment techniques and so on. ${ }^{5,6}$ It suggests that orthodontists should consider comprehensively to choose the most suitable bracket type.

The teeth more susceptible to EARR are the maxillary and mandibular incisors, and especially the maxillary central and lateral incisors. ${ }^{26}$ Sameshima et al. ${ }^{5}$ found that different race and age have different the amount of EARR in different teeth. For example, adult patients experienced more resorption than children did in the mandibular incisors and Asian patients were found to experience significantly less root resorption than white or Hispanic patients. ${ }^{5}$ This meta-analysis results indicate that self-ligating bracket is superior to controversial bracket in protecting maxillary central incisors from EARR (Fig. 2) in a long run. While there was no significant difference in the EARR of maxillary lateral incisors, mandibular central incisors and mandibular lateral incisors between these two types of brackets (Fig. 2). It suggests that self-ligating bracket is a better choice than conventional bracket when using in patients with more vulnerable maxillary central incisors.

The diagnosis of EARR has been mainly through radiographs. Among the nine included studies, three studies adopted CBCT (Cone-Beam Computed Tomography), two studies employed periapical radiographs, and the other four used panoramic radiographs. Although there was no significant difference among results of studies using different radiographic methods (Fig. 2), the varied distortions and magnifications of the types of radiographs could affect the overall results. Root resorption can be underestimated because of the inherent deficiency of panoramic or periapical views to show EARR in a facial direction. ${ }^{27}$ It is accepted that the 2-dimensional approaches including periapical films and panoramic radiographs may be insensitive to very minor changes in root lengths and may be less precise than CBCT in measuring EARR. ${ }^{28}$ Silveira et al. ${ }^{29}$ studied the ability of CBCT to diagnose EARR and suggested that $\mathrm{CBCT}$ has high sensitivity and excellent uniqueness. Thus, future studies should use $\mathrm{CBCT}$ to assess the amount of EARR in orthodontic treatment. However, the higher radiation dose of the $\mathrm{CBCT}$, especially to children and adolescents, should be considered.

\section{Limitations}

The aim this systematic review is to compare the EARR in patients using self-ligating with the EARR in patients using conventional brackets during fixed orthodontic treatment. After a comprehensive literature search and evaluation, ten studies ${ }^{13-22}$ were recruited in this systematic review, and nine studies ${ }^{13-17,19-22}$ were pooled for meta-analysis. Among these studies, only one was RCT ${ }^{11}$ and the others were CCTs ${ }^{14-22}$. The RCT did not describe whether allocation concealment or blinding method was adopted. Though this article was evaluated as high quality, it only got 4 Jadad scores. All of CCTs ${ }^{14-22}$ described diagnostic criteria, exclusion criteria and baseline conditions clearly and properly. They also included all subjects in the analysis, so there was no lost bias. Among CCTs ${ }^{14-22}$, seven of them identified confounding factors clearly, had reliable outcome indicators and appropriate statistical analysis, except for Lu et al. ${ }^{16}$. Whereas, all of CCTs ${ }^{14-22}$ did not mention grouping method, and seven of them also did not describe 
blinding method apart from Eissa et al. ${ }^{21}$. Because of the limitation of research quantity and quality, more fhigh-quality studies are needed to demonstrate the effect of different types of brackets on EARR.

\section{Conclusions}

Self-ligating bracket seems superior to conventional bracket in protecting maxillary central incisors from the EARR in a long run. However, there was no different influence on EARR of maxillary lateral incisors, mandible central incisors and mandible lateral incisors between these two types of brackets. There is a strong need for further research in certain directions through well-designed studies to provide more reliable evidences regarding this issue.

\section{Abbreviations}

EARR: External apical root resorption; CNKI: China National Knowledge Infrastructure; NLM: National Library of Medicine; SIGLE: System for Information on Grey Literature in Europe; WHOLIS: World Health Organization's library database; SLB: Self-ligating bracket; CB: Conventional bracket; SMD: Standardized mean difference.

\section{Declarations}

\section{Ethics approval and consent to participate}

Not applicable.

\section{Consent for publication}

Not applicable.

\section{Availability of data and material}

The datasets used and/or analysed during the current study are available from the corresponding author on reasonable request.

\section{Competing interests}

The authors declare that they have no competing interests.

\section{Funding}

This work was supported by the National Nature Science Foundation of China Nos.81960195 and 81760193. The funding support databases to this work in the collection of data.

\section{Authors' contributions}


$\mathrm{JX}, \mathrm{KY}, \mathrm{XW}, \mathrm{WH}$ conducted the literature search, performed the statistical analysis and draft the manuscript. YX designed the study and revised the manuscript. All authors read and approved the final version of submission.

\section{Acknowledgements}

Not applicable.

\section{References}

1. Malmgren O, Levander E. Minimizing orthodontically induced root resorption. In: Graber T, Eliades T, Athanasiou $A E$, editors. Risk management in orthodontics: experts' guide to malpractice. Chicago: Quintessence; 2004. p. 61-75.

2. Liany DM. Root resorption caused by orthodontic treatment: an evidence-based review. Semin Orthod. 1999;5:128-133.

3. Han G, Huang S, Den Hoff JW, et al. Root resorption after orthodontic intrusion and extrusion: an intraindividual study. Angle Orthodontist. 2005;75:912-918.

4. Segal GR, Schiffman PH, Tuncay OC, et al. Meta analysis of the treatment-related factors of external apical root resorption. Orthodontics \& Craniofacial Research. 2004;7:71-8.

5. Sameshima GT, Sinclair PM. Predicting and preventing root resorption: part II. Treatment factors. Am J Orthod Dentofacial Orthop. 2001;119:511-515.

6. Fleming SP, Dibiase AT, Lee RT. Randomized clinical trial of orthodontic treatment efficiency with selfligating and conventional fixed orthodontic appliances. Am J Orthod Dentofac Orthop. 2010;137:738-742.

7. Yi J, Li M, Li Y, et al. Root resorption during orthodontic treatment with self-ligating or conventional brackets: a systematic review and meta-analysis[J]. BMC Oral Health. 2016;16:125-133.

8. Moher D, Shamseer L, Clarke M, Ghersi D, Liberati A, Petticrew M, Shekelle P, Stewart LA. Preferred reporting items for systematic review and meta-analysis protocols (PRISMA-P) 2015 statement. Syst Rev 2015;4:1.

9. Deeks J, Higgins J, Altman D, Green S. Cochrane handbook for systematic reviews of interventions version 5.1.0 (updated March 2011). The Cochrane Collaboration 2011.

10. Higgins JPT, Green S (editors). Cochrane Handbook for Systematic Reviews of Interventions. Version 5.1.0[updated March 2011]. The Cochrane Collaboration, 2011. Available from cochranehandbook.org.

11. Jadad AR, Moore RA, Carroll D, et al. Assessing the quality of reports of randomized clinical trials: is blinding necessary? Controlled Clinical Trials. 1996;17:1-12.

12. Liu JP. System evaluation method of nonrandom trials: Part 1. Chinese Journal of Evidence-based Medicine. 2001;4:239-243. 
13. Liu Y, Guo HM. Comparison of root resorption between self-ligating and conventional brackets using cone-beam CT. Shanghai Journal of Stomatology. 2016;25:238-241.

14. Yang YKखZhu ZH. A clinical study of external apical root resorption of maxillary incisors in patients treated with conventional or self-ligating brackets. Modern Medical Journal. 2012;40:192-6.

15. Liu XQ, Sun XL, Yang Q, et al.. Comparative study on the apical root resorption between self -ligating and conventional brackets in extraction patients. Shanghai Journal of Stomatology. 2012;21:460-5.

16. Lu YP. Imageology study of different of root resorption after treatment of self-ligating and conventional preadjusted brackets. Stomatology. 2017;37:635-7.

17. Blake M, Woodside DG, Pharoah MJ, et al. A radiographic comparison of apical root resorption after orthodontic treatment with the edgewise and Speed appliances. American Journal of Orthodontics and Dentofacial Orthopedics. 1995;108:76-84.

18. Pandis N, Nasika M, Polychronopoulou A, et al. External apical root resorption in patients treated with conventional and self-ligating brackets. American Journal of Orthodontics and Dentofacial Orthopedics. 2008;134:646-651.

19. Chen W, Haq AAA, Zhou Y, et al. Root resorption of self-ligating and conventional preadjusted brackets in severe anterior crowding Class I patients: a longitudinal retrospective study. BMC Oral Health. 2015;15:115.

20. Sepolia S, Kushwah AP, Natt AS, et al. Retrospective Analysis of Different Bracket Systems used in the Treatment of Patients with Anterior Crowding: A Longitudinal Comparative Study. The Journal of Contemporary Dental Practice. 2016;17:687-691.

21. Eissa 0 , Carlyle T, Elbialy T, et al. Evaluation of root length following treatment with clear aligners and two different fixed orthodontic appliance: A pilot study. Journal of Orthodontic Science. 2018;7:11.

22. Qin F, Zhou Y. The influence of bracket type on the external apical root resorption in class I extraction patients-a retrospective study. BMC Oral Health. 2019;19:53.

23. Harradine NW. Self-ligating brackets: where are we now? Journal of Orthodontics. 2003;30:262-273.

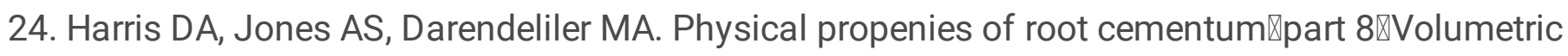
analysis of root resorption craters after application of controlled intrusive light and heavy orthodontic forces: a microcomputed tomography scan study. Am J Orhtod Dentofacial Orthop. 2006;130:639-647区

25. Barbagallo LJ, Jones AS, Petocz P, et a1. Physical properties of root cementum: part 10. Comparison of the effects of invisible removable thermoplastic appliances with light and heavy orthodontic forces on premolar camentum: a microcomputed-tomography study. Am J Orthod Dentofacial Orthop. 2008;133:218-227.

26. Iglesias-Linares A, Sonnenberg B, Solano B, et al. Orthodontically induced external apical root resorption in patients treated with fixed appliances vs removable aligners. Angle Orthod. 2017;87:310.

27. Peck JL, Sameshima GT, Miller A, et al. Mesiodistal root angulation using panoramic and cone beam CT. Angle Orthod. 2007;77:206-213. 
28. Armstrong D, Kharbanda OP, Petocz P, et al. Root resorption after orthodontic treatment. Australian Orthod Journal. 2006;22:153-160.

29. Silveira HD, Silveira H, Liedke GS, et al. Diagnostic ability of computed tomography to evaluate external root resorption in vitro. Dentomaxillofacial Radiology. 2007;36:393-6.

\section{Figures}

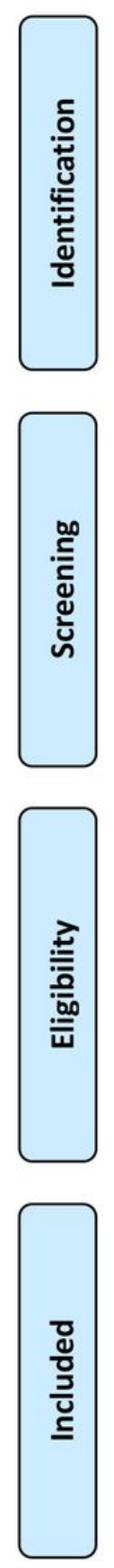

Records identified through database searching ( $n=686$ )

(PubMed: 59, OVID: 115, Cochrane Library: 44, EMBASE: 88,

FMRS: 56, CBM: 71, CNKI: 103, VIP: 25, WanFang Data: 125)
Additional records identified

through other sources $(n=2)$

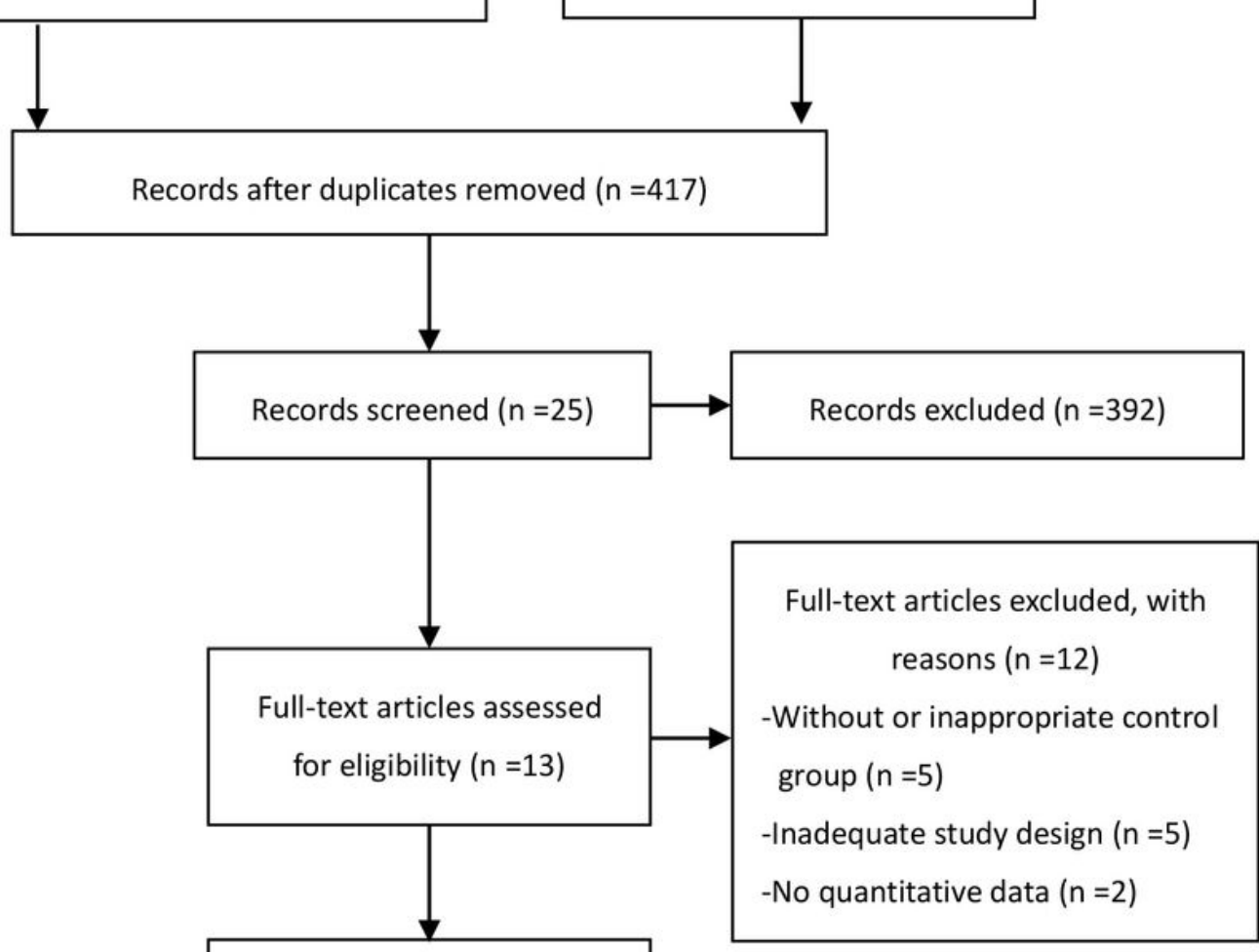

Studies included in

qualitative synthesis $(n=10)$

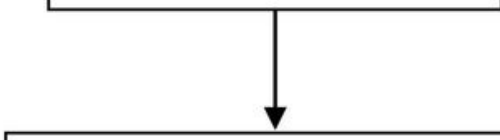

Studies included in quantitative synthesis (meta-analysis) $(n=9)$ 
Figure 1

Flow chart summarizing the literature search

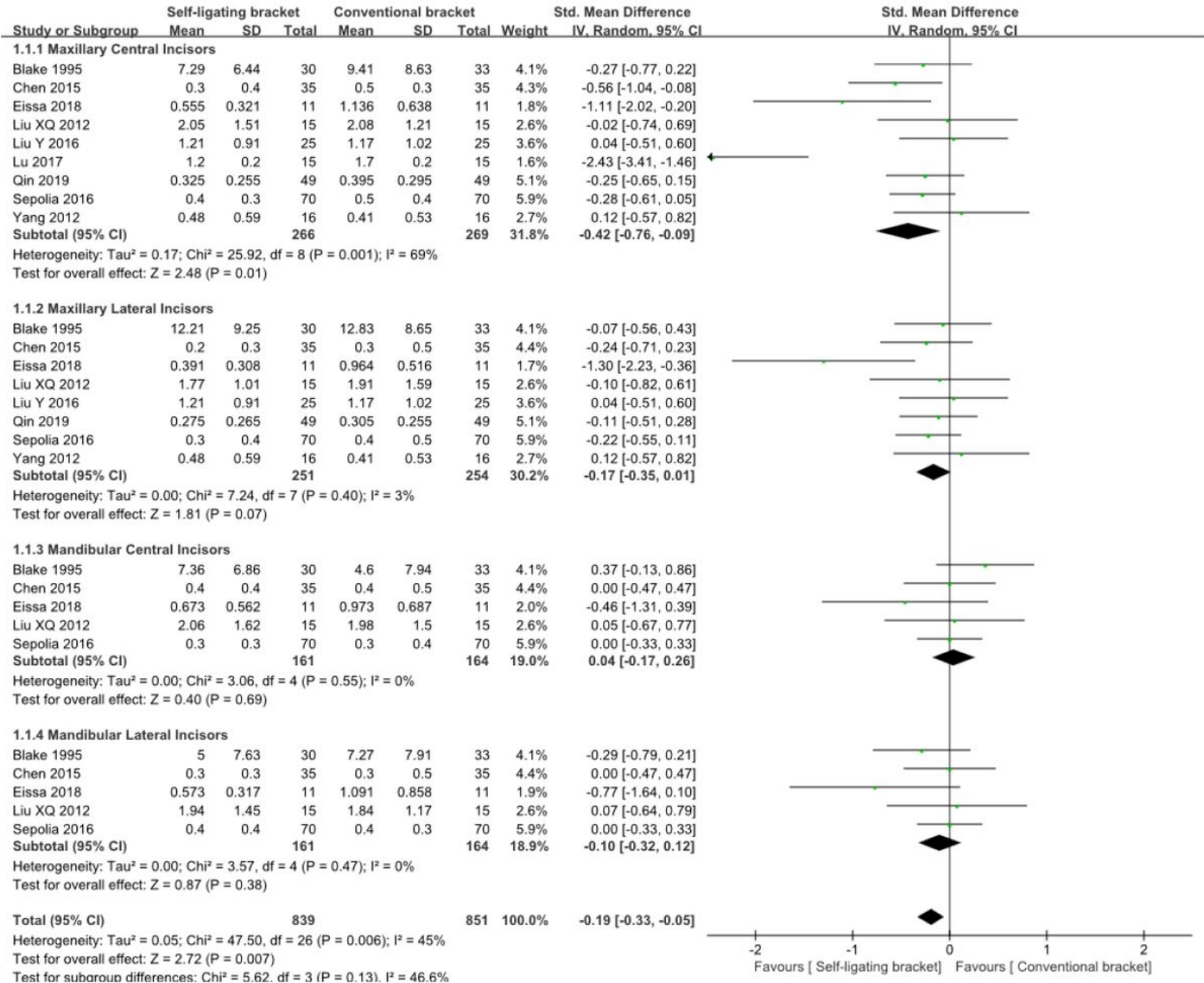

Figure 2

Meta-analysis and forest plot of ERAA values comparing self-ligating with conventional brackets 